\title{
Expression of the $\beta_{2}$ adrenoceptor partial agonist/antagonist activity of salbutamol in states of low and high adrenergic tone
}

\author{
A Grove, L C McFarlane, B J Lipworth
}

\begin{abstract}
Background - Salbutamol exhibits partial agonist/antagonist activity at airway $\beta_{2}$ receptors in vitro in that it attenuates the bronchorelaxant effect of the full agonist isoprenaline. The aim of the present study was to characterise the partial $\beta_{2}$ agonist/ antagonist activity of salbutamol in vivo during supine rest and exercise, in states of low and high adrenergic tone.

Methods - Eight normal subjects were randomised to receive single oral doses of salbutamol $2 \mathrm{mg}, 4 \mathrm{mg}, 8 \mathrm{mg}\left(S_{2}, S_{4}, S_{8}\right)$, placebo (PL), or propranolol $80 \mathrm{mg}$ (PR). The $\beta_{2}$ adrenoceptor responses were evaluated after supine rest and subsequently in response to maximal exercise.
\end{abstract}

Results - Salbutamol demonstrated a dose-related increase in resting heart rate and tremor and a fall in serum potassium level consistent with $\beta_{2}$ agonism. On exercise, the hyperkalaemic response was augmented by propranolol compared with placebo consistent with $\beta_{2}$ blockade: mean difference for delta response $(95 \%$ CI) PR $v$ PL was $0.60(0.02$ to 1.27$) \mathrm{mmol} / \mathrm{l}$. This effect also occurred with salbutamol in a dose-related fashion: $S_{8} v$ PL $0.33(0.01$ to $0.71) \mathrm{mmol} / \mathrm{l}, S_{8} v S_{2} 0.31(-0.02$ to 0.61$)$ mmol/1. Whilst propranolol blunted exercise heart rate in keeping with $\beta_{1}$ blockade, salbutamol had no effect. Exercise produced an increase in lymphocyte $\beta_{2}$ receptor binding density (Bmax) which was not affected by salbutamol. Plasma levels of adrenaline and noradrenaline at peak exercise were also unaltered by salbutamol in comparison with placebo.

Conclusions - In a state of low adrenergic tone at rest salbutamol produces effects consistent with $\beta_{2}$ agonism. In contrast, in a state of increased adrenergic tone during exercise salbutamol produced $\beta_{2}$ selective antagonism as evidenced by its effects on exercise-induced hyperkalaemia $\left(\beta_{2}\right)$ but not on exercise-induced tachycardia $\left(\beta_{1}\right)$. The effects of salbutamol on $\beta_{2}$ receptor density do not explain its effects on exerciseinduced hyperkalaemia since upregulation rather than downregulation was observed. This in vivo phenomenon of partial $\beta_{2}$ agonist/antagonist activity of salbutamol may be of relevance in the setting of acute asthma if adrenergic tone is increased.

(Thorax 1995;50:134-138)

Keywords: salbutamol, partial agonist/antagonist, $\beta_{2}$ adrenoceptor responses.
The $\beta_{2}$ agonist salbutamol exhibits in vitro partial $\beta_{2}$ agonist activity at cardiac $\beta_{2}$ adrenoceptors and full agonist activity at airway $\beta_{2}$ adrenoceptors. ${ }^{1-4}$ For example, in human or guinea pig right atrium salbutamol produces chronotropic and inotropic agonist activity ranging from $30 \%$ to $80 \%$ in comparison with maximal isoprenaline response. ${ }^{1-3}$ It is, however, important to note that the true expression of partial agonist/antagonist activity at $\beta_{2}$ adrenoceptors depends on the prevailing adrenergic tone. ${ }^{5}$ For example, in vitro an airway $\beta_{2}$ antagonist effect of salbutamol can be demonstrated when its effects on carbacholinduced bronchoconstriction are assessed in the presence of isoprenaline. ${ }^{6}$ In vivo the presence of low adrenergic tone - for example, during supine rest - will allow partial $\beta_{2}$ agonist activity of salbutamol to be expressed. ${ }^{7}$ In contrast, when adrenergic tone is raised - for example, during exercise - it would be expected that salbutamol should behave as a $\beta_{2}$ antagonist relative to the activity of adrenaline. It should therefore be possible to characterise the partial $\beta_{2}$ agonist/antagonist profile of salbutamol by comparing effects at rest and in response to exercise.

The $\beta_{2}$ mediated adrenergic response to exercise may be quantified by evaluating the hyperkalaemic response. During exercise the $\alpha_{1}$ receptor-mediated potassium efflux from skeletal muscle is modulated by membrane bound $\beta_{2}$ receptor-linked sodium/potassium ATPase which drives potassium into cells. Thus, as one might predict from first principles, $\beta_{2}$ adrenoceptor antagonism with ICI $118551^{8}$ or propranolol ${ }^{9}$ results in augmentation of exercise-induced hyperkalaemia, whilst phentolamine produces blunting of this response. ${ }^{9}$ The aim of the present study was therefore to investigate the partial $\beta_{2}$ agonist/antagonist activity of salbutamol at rest and in response to exercise using propranolol as a positive control for $\beta_{1} / \beta_{2}$ adrenoceptor antagonism.

\section{Methods}

SUBJECTS

Eight normal, non-smoking men with a mean (SE) age of 25 (1.35) years were recruited. All had a normal screening examination including 12-lead ECG, routine haematology and biochemistry before entry into the study. None were taking regular medication. The study was approved by the local ethics committee and subjects gave written informed consent. 
STUDY DESIGN

A double blind, randomised (latin square) placebo controlled crossover design was used. Subjects attended the laboratory on five occasions separated by at least 72 hours. They were instructed to fast overnight and to take the study medication 1.5 hours before the laboratory visit. Treatment consisted of single oral doses of placebo (PL), salbutamol $2 \mathrm{mg}$ $\left(\mathrm{S}_{2}\right)$, salbutamol $4 \mathrm{mg}\left(\mathrm{S}_{4}\right)$, salbutamol $8 \mathrm{mg}$ $\left(\mathrm{S}_{8}\right)$, and propranolol $80 \mathrm{mg}(\mathrm{PR})$.

\section{PROTOCOL}

On arrival at the laboratory a cannula was inserted into an antecubital vein to facilitate blood sampling. Subjects then rested supine for 30 minutes before taking baseline measurements (post-drug) of heart rate and finger tremor. A post-drug blood sample was also taken for analysis of serum potassium levels. Analysis of lymphocyte $\beta_{2}$ adrenoceptor density (Bmax) and binding affinity $(\mathrm{Kd})$ were only performed on days when subjects received placebo or salbutamol. Subjects then underwent a standardised three minute exercise step test to evaluate the maximal heart rate response. ${ }^{10}$ Heart rate was monitored throughout the test and the peak exercise heart rate recorded. Immediately after completion of the exercise a further blood sample was taken for analysis of serum potassium, plasma catecholamines, Bmax, and $\mathrm{Kd}$.

\section{MEASUREMENTS}

Heart rate was monitored and recorded using a 12-lead electrocardiograph with stress test adaptor (HP4700A, Hewlett Packard, Palo Alto, California, USA), and calculated from the mean of five consecutive $R-R$ intervals. Postural finger tremor was measured by a previously validated method $^{7}$ using an accelerometer transducer (Entran Ltd, Ealing, UK) attached to the distal phalanx of the middle finger. Four recordings were made and the results stored on computer disc for subsequent spectral analysis of total tremor power $>2 \mathrm{~Hz}$ (with units of $\mathrm{mg}^{2} / \mathrm{s}$ ) using computer assisted autocovariance.

Serum potassium levels were measured by flame photometry (IL943 analyser, Instrumentation Lab Ltd, Warrington, UK) with each sample analysed in duplicate. The normal reference range for our laboratory is $3.5-5.5 \mathrm{mmol} / \mathrm{l}$, and the coefficients of variability for analytical imprecision within and between assays were $0.38 \%$ and $0.44 \%$, respectively. Plasma levels of noradrenaline and adrenaline were assayed by the double isotope radioenzymatic method of Brown and Jenner." The intra-assay coefficient of variation for this method in our laboratory is $8.0 \%$ and interassay coefficient of variation is $11 \cdot 1 \%$.

To determine Bmax and binding affinity (expressed as the dissociation constant for the radiolabelled antagonist - that is, $\mathrm{Kd}) 40 \mathrm{ml}$ of whole blood was collected into tubes containing ethylene diaminetetraacetic acid. The methodology has previously been described and is given in brief here. ${ }^{12}$ The blood was diluted to $50 \mathrm{ml}$ with phosphate buffered saline (PBS) and two equal aliquots were centrifuged with $15 \mathrm{ml}$ Lymphoprep (Nycomed Pharma AS, Oslo, Norway) and the lymphocyte layer removed. Following two further washes with PBS and centrifugation the lymphocyte pellet was resuspended in $5 \mathrm{ml}$ PBS prior to lymphocyte counting. ${ }^{125}$ I-iodocyano-pindolol (ICYP) (Nen-du Pont (UK) Ltd, Stevenage, UK) was used to determine Bmax and $\mathrm{Kd}$. Eight concentrations of ICYP between $5 \mathrm{pM}$ and $160 \mathrm{pM}$ were used with CGP12177 (Ciba-Geigy, Basle, Switzerland) being added to half the tubes to prevent ICYP binding to receptor sites, thus allowing non-specific binding to be evaluated. Specific receptor binding was calculated from total minus non-specific binding. The intraassay coefficient of variation for analytical imprecision was $10 \cdot 29 \%$ for $B \max$ and $5 \cdot 85 \%$ for Kd.

\section{STATISTICAL ANALYSIS}

Finger tremor data were transformed using logarithm to base 10 to achieve conformation with a normal distribution prior to analysis. Data were analysed using a Statgraphics statistical software package (STSC Software Publishing Group, Rockville, USA). Comparisons were made by multifactorial analysis of variance (MANOVA) using subjects, treatments, and periods as within factors for analysis. Where the overall MANOVA was significant Duncan's multiple range testing was then applied to establish where differences between treatments were significant, and in these cases the $95 \%$ confidence interval for the differences between the means was also calculated. A probability value of $\mathrm{p}<0.05$ (two tailed) was considered as being of significance for all tests. Values are given in the text either as means (SE) for each treatment, or as mean differences and $95 \%$ confidence intervals (CI) for differences between treatments.

\section{Results}

SUPINE REST (AFTER DRUG) (fig 1A-C)

Salbutamol produced a dose-related stimulation of $\beta_{2}$ receptors as evidenced by significant increases in resting heart rate and finger tremor, and a fall in serum potassium level. These effects were significantly different $(\mathrm{p}<0.05)$ from placebo at $4 \mathrm{mg}$ and $8 \mathrm{mg}$ doses; resting heart rate: (as mean difference) $\mathrm{S}_{4} v \mathrm{PL}$ 18 (4 to 31) beats/min, $\mathrm{S}_{8} v$ PL 21 (7 to 34) beats $/ \mathrm{min}$, finger tremor: $\mathrm{S}_{4} v$ PL $0.68(0.12$ to 1.24$) \log$ units, $S_{8} v$ PL $0.97(0.39$ to 1.54$)$ $\log$ units, and serum potassium: $\mathrm{S}_{4} v \mathrm{PL}-0.45$ $(-0.86$ to -0.03$) \mathrm{mmol} / \mathrm{l}, \mathrm{S}_{8} v \mathrm{PL}-0.59$ $(-1.00$ to -0.17$) \mathrm{mmol} / \mathrm{l}$.

EXERCISE RESPONSES (fig 2)

Propranolol significantly $(\mathrm{p}<0.05)$ attenuated the $\beta_{1}$ mediated heart rate delta response to exercise with placebo, indicating $\beta_{1}$ adrenoceptor antagonism, whilst salbutamol had no effect (fig 2A): PR $v$ PL -40 ( -60 to -21 ) 

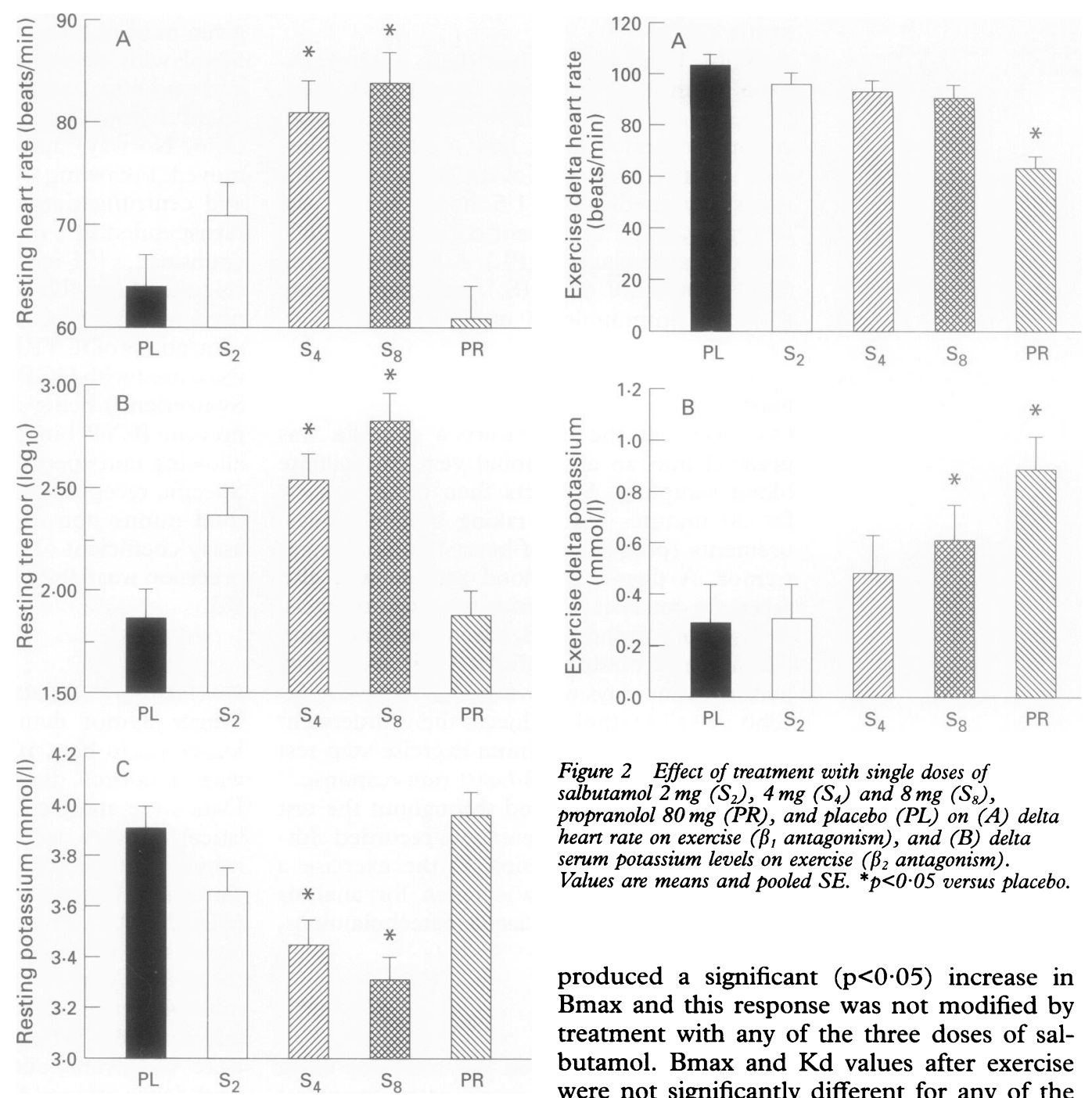

Figure 2 Effect of treatment with single doses of salbutamol $2 \mathrm{mg}\left(S_{2}\right), 4 \mathrm{mg}\left(S_{4}\right)$ and $8 \mathrm{mg}\left(S_{8}\right)$, propranolol $80 \mathrm{mg}(\mathrm{PR})$, and placebo (PL) on $(A)$ delta heart rate on exercise ( $\beta$, antagonism), and $(B)$ delta serum potassium levels on exercise ( $\beta_{2}$ antagonism). Values are means and pooled $S E .{ }^{*} p<0.05$ versus placebo.

Figure 1 Effect of treatment with single doses of salbutamol $2 \mathrm{mg}\left(S_{2}\right), 4 \mathrm{mg}\left(S_{4}\right)$, and $8 \mathrm{mg}\left(S_{8}\right)$ propranolol $80 \mathrm{mg}(P R)$, and placebo $(P L)$ on $(A)$ resting heart rate, $(B)$ postural finger tremor, and $(C)$ serum potassium levels. Values are means and pooled SE. $* p<0.05$ versus placebo.

beats/min. Propranolol significantly $(p<0 \cdot 05)$ potentiated the $\beta_{2}$ mediated rise in potassium (delta response) on exercise compared with placebo, consistent with its known $\beta_{2}$ blockade: PR $v$ PL $0.60(0.02$ to 1.27$) \mathrm{mmol} / \mathrm{l}$. Salbutamol likewise potentiated the exercise-induced delta response in dose-related fashion reaching significance $(p<0.05)$ compared with placebo at the $8 \mathrm{mg}$ dose (fig 2B): $\mathrm{S}_{8} v \mathrm{PL}$ $0.33(0.01$ to 0.71$) \mathrm{mmol} / 1$. The exercise delta response was significantly higher with $S_{8}$ than with $S_{2}: 0.31(-0.02$ to 0.61$) \mathrm{mmol} / \mathrm{l}$. Mean (SE) absolute levels of potassium at peak exercise were significantly higher $(p<0.05)$ after propranolol, but not after salbutamol, in comparison with placebo: PL $4 \cdot 17(0 \cdot 15), S_{2} 3.97$ $(0 \cdot 10), S_{4} 3.94(0 \cdot 15), S_{8} 3.94(0 \cdot 17), P R$ $4 \cdot 84(0 \cdot 20) \mathrm{mmol} / \mathrm{l}$. There were, however, no significant differences in peak exercise potassium levels between salbutamol doses and placebo.

LYMPHOCYTE $\beta_{2}$ RECEPTOR PARAMETERS (table) Resting Bmax was not altered by treatment with salbutamol compared with placebo. Exercise

produced a significant $(\mathrm{p}<0 \cdot 05)$ increase in Bmax and this response was not modified by treatment with any of the three doses of salbutamol. Bmax and $\mathrm{Kd}$ values after exercise were not significantly different for any of the doses of salbutamol or in comparison with PL.

\section{PLASMA CATECHOLAMINES}

Plasma levels of noradrenaline or adrenaline at peak exercise were not significantly altered by salbutamol in comparison with placebo. The plasma level of noradrenaline was not significantly altered by propranolol, whilst the plasma adrenaline level was significantly higher with propranolol $(p<0.05)$ than with all other treatments. Values for adrenaline were PL 0.87 $(0.49), S_{2} 0.65(0.27), S_{4} 0.55(0.22), S_{8} 0.76$ $(0 \cdot 16)$, PR $2 \cdot 24(1 \cdot 04) \mathrm{nmol} / \mathrm{l}$, and for noradrenaline were PL 10.78 (3.43), $\mathrm{S}_{2} 8.52$ $(1 \cdot 66), \mathrm{S}_{4} 10 \cdot 24(1 \cdot 89), \mathrm{S}_{8} 12 \cdot 14(3 \cdot 26), \mathrm{PR}$ $10 \cdot 48(1 \cdot 24) \mathrm{nmol} / \mathrm{l}$.

\section{Discussion}

The results of this study show that, in a resting state with low endogenous adrenergic tone, salbutamol expressed dose-related $\beta_{2}$ adrenoceptor agonist activity by increasing heart rate and postural finger tremor and lowering the serum potassium level. Even at the highest dose of $8 \mathrm{mg}$ salbutamol has previously been shown to exhibit $\beta_{2}$ specific agonist activity as evidenced by the lack of effect of bisoprolol, a $\beta_{1}$ selective blocker, on chronotropic or inotropic response. ${ }^{13}$ In contrast, during exercise, when adrenergic tone was high, salbutamol po- 
Mean $\left(95 \%\right.$ CI) for the difference versus placebo in lymphocyte $\beta_{2}$ receptor density (Bmax) and binding affinity, expressed as the dissociation constant for ICYP binding $(K d)$, at rest and immediately after exercise

\begin{tabular}{|c|c|c|c|c|}
\hline \multirow[t]{2}{*}{ Treatment } & \multicolumn{2}{|l|}{ Resting } & \multicolumn{2}{|l|}{ Exercise } \\
\hline & $\begin{array}{l}\text { Bmax } \\
\left(\mathrm{fmol} / 10^{6} \mathrm{cells}\right)\end{array}$ & $\begin{array}{l}\text { Kd } \\
(\text { pmolll) }\end{array}$ & $\begin{array}{l}(\mathrm{Bmax} \\
\left(\mathrm{fmol} / 10^{6} \text { cells }\right)\end{array}$ & $\begin{array}{l}\text { Kd } \\
\text { (pmolll) }\end{array}$ \\
\hline $\begin{array}{l}\mathrm{PL} \\
\mathrm{S}_{2} \\
\mathrm{~S}_{4} \\
\mathrm{~S}_{8}\end{array}$ & $\begin{array}{l}2 \cdot 52 \\
2 \cdot 79 \\
(-0 \cdot 68 \text { to } 1 \cdot 23) \\
2 \cdot 34 \\
(-1 \cdot 13 \text { to } 0 \cdot 77) \\
2 \cdot 83 \\
(-0.64 \text { to } 1 \cdot 27)\end{array}$ & $\begin{array}{l}14 \cdot 56 \\
13 \cdot 45 \\
(-5 \cdot 60 \text { to } 3 \cdot 38) \\
9 \cdot 86^{*} \\
(-8 \cdot 42 \text { to }-0.97) \\
13 \cdot 29 \\
(-5 \cdot 75 \text { to } 3 \cdot 22)\end{array}$ & $\begin{array}{l}3.67 \dagger \\
3.66 \dagger \\
(-1.09 \text { to } 1.07) \\
3.12 \dagger \\
(-1.63 \text { to } 0.54) \\
3.50 \dagger \\
(-1.25 \text { to } 0.91)\end{array}$ & $\begin{array}{l}17 \cdot 70 \\
15 \cdot 68 \\
(-9 \cdot 03 \text { to } 5 \cdot 01) \\
16 \cdot 00 \dagger \\
(-8 \cdot 71 \text { to } 5 \cdot 33) \\
16 \cdot 47 \\
(-8.24 \text { to } 5 \cdot 80)\end{array}$ \\
\hline
\end{tabular}

${ }^{*} \mathrm{p}<0.05$ versus placebo.

$t p<0.05$ between resting and exercise values.

$\mathrm{PL}=$ placebo; $\mathrm{S}_{2}, \mathrm{~S}_{4}, \mathrm{~S}_{8}=$ salbutamol $2 \mathrm{mg}, 4 \mathrm{mg}$, and $8 \mathrm{mg}$.

tentiated the hyperkalaemic delta response in a dose-related fashion, an effect similar to that observed with propranolol and consistent with $\beta_{2}$ adrenoceptor antagonism.

To understand the above findings it is important to consider the $\beta$ adrenoceptor subtypes responsible for mediating the heart rate and potassium responses to exercise. Blockade of $\beta_{2}$ adrenoceptors by propranolol ${ }^{9}$ or by ICI $118551^{8}$ has previously been shown to augment exercise-induced hyperkalaemia. This occurs as a result of antagonising the effect of adrenaline on intracellular potassium influx, mediated via the membrane bound $\beta_{2}$ adrenoceptor linked $\mathrm{Na} / \mathrm{K}$-ATPase pump. This is clearly demonstrated by the enhancement of exercise-induced hyperkalaemia by digitalis which directly inhibits the $\mathrm{Na} / \mathrm{K}$-ATPase pump. ${ }^{14}$

The effects of salbutamol on the serum potassium level must be considered in the light of the starting level before exercise (after salbutamol) and the final level at peak exercise. If the effect of salbutamol was merely due to a lower starting value one might expect peak exercise potassium levels also to be lowered to the same degree after salbutamol compared with placebo. The delta response (post - preexercise) would then be the same at all doses of salbutamol. Our results showed that absolute peak exercise levels of potassium were comparable for placebo and all doses of salbutamol. This explains why the delta response was augmented by salbutamol compared with placebo.

The fact that the final achieved levels of potassium following exercise were similar clearly suggests that the mechanism was not due to simple "functional antagonism" due to a lowered baseline. Furthermore, whilst the baseline pre-exercise potassium level was not altered by propranolol compared with placebo, there was a significant increase in the delta response to exercise. This therefore suggests that the baseline pre-exercise potassium level did not have any confounding effects on the subsequent delta response, and that the observed effects of salbutamol on exerciseinduced hyperkalaemia were, like propranolol, due to $\beta_{2}$ adrenoceptor antagonism. The absence of any effect of salbutamol on the plasma level of adrenaline also suggests that postjunctional antagonism of skeletal muscle $\beta_{2}$ adrenoceptors rather than prejunctional antagonism of adrenomedullary $\beta_{2}$ adrenoceptors was the most likely mechanism.
On maximal exercise during the step test, there is a much greater rise in noradrenaline levels than in levels of adrenaline. Vagal tone is also attenuated during exercise, although it has been shown with atropinisation that the predominant chronotropic effect is $\beta$ adrenoceptor mediated. ${ }^{10}$ The $\beta_{1}$ adrenoceptor activity of noradrenaline is mainly responsible for the exercise-induced increase in heart rate, as evidenced by the lack of effect of selective $\beta_{2}$ blockade with ICI $118551 .^{1516}$ The attenuation of exercise-induced heart rate by propranolol in our study was consistent with its known degree of $\beta_{1}$ blockade. In this respect the lack of effect of salbutamol on exercise-induced tachycardia is therefore indicative that the partial antagonism of salbutamol is $\beta_{2}$ selective.

An increase in $\beta_{2}$ receptor density occurred in response to exercise and this was unaffected by prior treatment with salbutamol. Thus, effects of salbutamol on $\beta_{2}$ receptor density cannot therefore be invoked to explain the effects of salbutamol on exercise-induced hyperkalaemia as upregulation rather than downregulation was observed. The apparent rise in $\mathrm{Kd}$ with $4 \mathrm{mg}$ salbutamol can be explained solely on the basis of a lower baseline value since the values after exercise did not significantly differ between doses of salbutamol. The observed rise in Bmax with exercise is consistent with previously published data. ${ }^{17-20}$ The precise mechanism for this response remains unclear, although there is evidence to suggest that it may be the result of catecholamine-induced changes in the composition of the circulating pool of lymphocytes, such that cells relatively rich in $\beta_{2}$ receptors are released into the circulation to a greater extent than those with a lower receptor density. ${ }^{21-24}$

In the present study the systemic responses of normal volunteers were studied. It is, however, conceivable that, even in the airway, in the presence of raised levels of endogenous adrenergic tone, salbutamol may act as an antagonist at bronchial $\beta_{2}$ adrenoceptors. In this regard there is in vitro evidence in guinea pig airway that salbutamol, despite being a full agonist when given alone, was shown to antagonise competitively the relaxant effect of isoprenaline in the presence of carbachol-induced bronchoconstriction. ${ }^{6}$ This illustrates the important principle that it is only possible properly to assess agonist/antagonist activity in the presence of a full agonist, whether it be isoprenaline in vitro or adrenaline in vivo. Further studies in asthmatic subjects may therefore be warranted to investigate this effect in vivo, with its possible relevance in the setting of acute asthma if adrenergic tone is increased, in a patient who may also be taking high doses of $\beta_{2}$ agonists. Furthermore, it would be interesting to know whether there are differences in activity between partial $\beta_{2}$ agonists such as salbutamol and salmeterol and full agonists such as fenoterol and formoterol, particularly when adrenergic tone is increased.

1 Wilson C, Lincoln C. $\beta$-adrenoceptor subtypes in human, rat, guinea pig, and rabbit atria. $\mathcal{F}$ Cardiovasc Pharmacol 1984;6:1216-21.

2 O'Donnell SR. An examination of some $\beta$-adrenoceptor 
stimulants for selectivity using the isolated trachea and atria of the guinea pig. Eur $\mathcal{F}$ Pharmacol 1972;19:371-9.

3 Wagner J, Reinhardt D, Schumann HJ. Comparison of the bronchodilator and cardiovascular actions of isoprenaline, Th $1165 \mathrm{a}$, terbutaline and salbutamol in cats and isolated organ preparations. Res Exp Med 1973;162:49-62.

4 Linden A, Bergendal A, Ulman A, Skoogh B-E, Lofdahl C-

G. Salmeterol, formoterol, and salbutamol in the isolated $\mathrm{G}$. Salmeterol, formoterol, and salbutamol in the isolated
guinea pig trachea: differences in maximum relaxant effect guinea pig trachea: differences in maximum relaxant effect
and potency but not in functional antagonism. Thorax and potency but

5 Waller DG. $\beta$-adrenoceptor partial agonists: a renaissance in cardiovascular therapy? $\mathrm{Br} \mathcal{F}$ Clin Pharmacol 1990;30 157-71.

6 O'Donnell SR, Wanstall JC. Evidence that the efficacy (intrinsic activity) of fenoterol is higher than that of salbutamol on $\beta$-adrenoceptors in guinea pig trachea. Eur $\mathcal{F}$ Pharmacol 1978;47:333-40.

7 Lipworth BJ, McDevitt DG. $\beta$-adrenoceptor responses to inhaled salbutamol in normal subjects. Eur 7 Clin Pharmacol 1989;36:239-45.

8 Struthers AD, Quigley C, Brown MJ. Rapid changes in plasma potassium during a game of squash. Clin Sci 1988 74:397-401.

9 Williams ME, Gervino EV, Rossa RM, Landsbergh, Young JB, Silva P, et al. Catecholamine modulation of rapid potassium shifts during exercise. $N$ Engl $\mathcal{f}$ Med 1985;312. 823-7.

10 Carruthers S, Shanks RG, McDevitt DG. Intrinsic heart rate on exercise and the measurement $\beta$-adrenoceptor blockade. Br f Clin Pharmacol 1976;3:991-9.

11 Brown MJ, Jenner DA. Novel double isotope technique for enzymatic assay of catecholamines permitting high precision sensitivity and plasma sample capacity. Clin Sci precision sensiti

12 Newnham DM, Coutie WJR, McFarlane LC, Lipworth BJ. Comparison of parameters of in vitro lymphocyte $\beta_{2}$ adrenoceptor function in normal and asthmatic subjects Eur 7 Clin Pharmacol 1993;43:535-8.

13 Wheeldon NM, McDevitt DG, Lipworth BJ. Cardiac effects of the $\beta$-adrenoceptor agonist BRL 35135 in man. Brf Clin Pharmacol 1994;37:363-9.

14 Norgaard A, Botker HE, Klitgaard NA, Toft P. Digitalis enhances exercise-induced hyperkalaemia. Eur f Clin Pharmacol 1991;41:609-11.

15 Arnold JMO, O'Connor PC, Riddell JG, Harron DWG, Shanks RG, McDevitt DG. Effects of the $\beta_{2}$-adrenoceptor antagonist ICI 118551 on exercise tachycardia and isoprenaline induced $\beta$-adrenoceptor responses in man. $B r \mathcal{F}$ Clin Pharmacol 1985;19:619-30.

16 Pringle TH, Riddell JG, Shanks RG. Characterisation of the $\beta$-adrenoceptors which mediate isoprenaline-induced the $\beta$-adrenoceptors which mediate isoprenaline-induced changes in finger tremor and cardiovascular

17 Butler J, Kelly JG, O'Malley K, Pidgeon F. $\beta$-adrenoceptor adaptation to acute exercise. F Physiol 1983;334:113-7.

18 Tohmeh JF, Cryer DE. Biphasic adrenergic modulation of $\beta$-adrenergic receptors in man. Agonist induced early increment and late decrement in $\beta$-adrenergic receptor number. $\mathcal{F}$ Clin Invest 1980;65:836-40.

19 Graafsma SJ, Van Tits L-J, van Heijst P, Reyenga S, Lenders JWM, Rodrigues de Miranda JF, et al. Adrenoceptors on blood cells in patients with essential hypertension before and after mental stress. $₹$ Hypertension 1989;7:519-24.

20 Brodde OE, Paul AE, Wang XL, Michel MC, Galal O. Dynamic exercise induced increase in lymphocyte $\beta_{2^{-}}$ adrenoceptors. Abnormality in essential hypertension and its correction by antihypertensives. Clin Pharmacol Ther 1987;41:371-9.

21 Murray DR, Irwin M, Rearden A, Ziegler M, Motulsky H, Maisel A. Sympathetic and immune interactions during dynamic exercise mediation via a $\beta_{2}$-adrenergic-dependent mechanism. Circulation 1992;86:203-13.

22 Maisel A, Knowlton KV, Fowler P, Rearden A, Ziegler MG, Mohlsky HJ, et al. Adrenergic control of circulating lymphocyte subpopulations. Effects of congestive heart failure, dynamic exercise and terbutaline treatment. F Clin failure, dynamic exercise
Invest 1990;85:462-7.

23 Maisel A, Harris T, Rearden CA, Michel MC. $\beta$-adrenergic receptors in lymphocyte subsets after exercise. Alterations in normal individuals and patients with congestive heart failure. Circulation 1990;82:2003-10.

24 Van Tits LJH, Michel MC, Grosse-Wilde H, Happel M, Eigler FW, Soliman A, et al. Catecholamines increase lymphocyte receptors via a $\beta_{2}$-adrenergic, spleen-dependent process. Am $\mathcal{F}$ Physiol 1990;258:E191-202. 